time, might eventually unite, and regain its normal functions.

I have treated several other cases of necrosis-most of them in the tibia-in the manner above recommended, and always with success.

Southampton, July 11, 1844.

\section{CASE OF SPONTANEOUS RUPTURE OF THE UTERUS.}

By W. Arnold, M.D., Kingston, Jamaica.

The following remarks were made by Dr. Henriques, who was first called to the patient on the 20th of November, 1842 :-

Mrs. Brown, a black woman, about 35 years of age, plethoric, of leuco-phlegmatic temperament, remarkably fat, is the mother of several children; in giving birth to them she invariably suffered, and indeed was ill prior and subsequent to delivery.

At ten o'clock this morning, whilst at breakfast, she was suddenly seized with uterine pains, by no means severe, and these pains ceased as suddenly, but were succeeded by nausea, continued syncope, and uterine hremorrhage. She was at the full term of gestation.

She was entirely free from pain; on the arrival of Dr. Henriques she complained however of great weakness. Several clots of blood were taken from the vagina, but no active hæmorrhage existed at the time; the neck of the uterus was soft, and dilated only to admit the introduction of the little finger; the pulse full, but easily compressed. Imagining that internal hæmorrhage was going on, she was bled, and took an opiate. Two hours after, upon examination, she was found precisely in the same state; the fulness of the pulse somewhat diminished, and the disposition to syncope more prolonged. Large doses of the secale cornutum were given, but this powerful medicine produced no effect.

At nine, p.m., there were evident signs of sinking, without any appreciable cause. No pain, no hæmorrhage, no further dilatation.

It was digreed to have a consultation, and I received a note from Dr. Henriques requesting me to meet him.

The patient was lying in a quiescent state, free from pain; the pulse weak, about 100 ; she replied to questions, but nothing satisfactory was elicited.

We agreed in the propriety of effecting delivery by forcibly dilating the uterus, which did not permit of a free examination, although I brought away one or the clots of blood, which nearly filled the vagina. Internal hæmorrhage was unquestionable, although not active, delivery at this juncture was evidently impracticable. Dr. Henriques proposed to try the effect of belladonna, with the view to dilatation, and to await one or two hours. At twelve o'clock the uterus admitted of a free examination, and delivery by turning was effected; the placenta was extracted entire, and what was equally surprising to us both, not a single drop of blood was lost, if we except one or two clots taken away just before the birth.

She died at three in the morning, without a struggle.

Post-mortem examination about noon on the 21 st. A triangular incision was made in the hypogastric region; in this incision the abdominal parietes were comprised, and on turning downwards the angular flap, the uterus was brought into view. Here was presented to us a scene as unexpected as it was extraordinary; immense clots of blood surrounded the uterus, filling up the whole abdominal cavity, the removal of which enabled us to lift the uterus, and now it was that we discovered an extensive rupture on. the posterior surface.

The uterus was accordingly dissected out, and carefully examined, its texture appeared unusually soft; the mucous surface bore evident traces of inflammatory action at different points, and the external serous covering also presented erysipelatous discolouration.

REMARKS.

This case is novel and extraordinary :-first, beeause the rupture appeared to be the result of inflammatory action, which gave no pain except that described when the injury took place, which pain was considered the premonitory pain of approaching labour; secondly, because softening of the uterine tissue is very rare; thirdly, because the fotus and placenta maintained their positions instead of escaping into the abdominal cavity.

Kingston, Jamaica, May 7, 1844.

\section{CASE OF INVERSIO UTERI.}

By William Joseph Square, Esq., Surgeon to the South Devon and East Cornwall Hospital, to the Plymouth Eye Infirmary, \&c.

TO THE EDITOR OF THE PROVINCIAL MEDICAL AND Sir,

In accordance with a request, expressed by $\mathrm{Mr}$. Crosse in a late number of your Journal, I beg to forward to you a case of inversion of the uterus, which will probably be interesting to some of your readers.

On the 14th of February, 1840, I was summoned in haste to Mrs. D., a powerful woman, having a large pelvis, who was delivered on the $3 d$ of the month, of twin children. She had been attended by Mr. who stated that her labour, (her first one,) had been perfectly natural, and completed in an hour and a quarter after he first visited her, that the placentæ were expelled with very trifling manual assistance, just sufficient to disengage them from the vagina, and that their expulsion was followed by a very small quantity of blood, certainly not more than three or four ounces. This statement accorded in every particular, with that of the patient and her friends.

For eight days she remained in bed, and was quite well. On the evening of the eighth day she dressed, and sat up, and while in the sitting posture experienced a trifling uterine hæmorrhage. Two days afterwards, while sitting up, this was repeated, and to a larger amount.

To-night, she had lost about a quart of florid blood. On my arrival she was seated on a chair, feeble, and very pale. I caused her to be placed in bed, and covered her with the sheet only. I then made firm pressure on the abdomen with a pad and bandage, and ordered one scruple of secale cornutum, infused in boiling water, to be taken every two hours.

15th. The hæmorrhage has ceased. A sanguineoserous discharge continues. She presents the ordinary constitutional symptoms of a large loss of blood. 